\title{
Mayer-Rokitansky-Küster-Hauser Syndrome with Rare Findings of Crossed Fused Renal Ectopia and Ovarian Serous Cystadenoma
}

\author{
${ }^{1}$ Mona Asnani, ${ }^{2}$ Kumkum Srivastava, ${ }^{3}$ Lubna Inam, ${ }^{4}$ Shipra Kunwar
}

\section{ABSTRACT}

The Mayer-Rokitansky-Küster-Hauser (MRKH) syndrome occurs in one of 4,000 to 5,000 female births and is characterized by normal development of secondary sexual, congenital aplasia of uterus and upper part $(2 / 3)$ of vagina, and normal fallopian tubes and ovaries. Therefore, individuals with MRKH syndrome are at normal risk of developing ovarian neoplasms.

We report a case of 19 years old unmarried female who was admitted to the hospital with pain in lower abdomen for 7 months. She was having primary amenorrhea. Gynecological examination revealed a blind vaginal pouch. Rectal examination revealed a large left-sided $8 \mathrm{~cm}$ cystic mass which was mobile with a smooth surface. Uterus was not palpable. Phenotypic sex was female. Breast development, axillar and pubic hair development were normal. Abdominopelvic ultrasonography showed left-sided crossed fused renal ectopia and a heterogeneous hypoechoic cystic mass with dense internal echoes on left-side. Uterus was not visualized. Intravenous pyelography also confirmed the finding of left-sided crossed fused renal ectopia. At laparotomy, a $10 \times 8 \mathrm{~cm}$ cystic hemorrhagic ovarian mass with a single twist of pedicle was found, with a normal right ovary and bilateral tubes. A small hypoplastic unicornuate uterus was present. Cervix was absent. Left-sided Salpingo-oophorectomy was done and tissue was sent for histopathology, which revealed ovarian serous cyst adenoma.

All patients with vaginal agenesis must be regarded primarily as a MRKH syndrome and they must be investigated to establish whether there were any associated congenital anomalies.

Keywords: Crossed renal ectopia, Primary amenorrhea, Unicornuate uterus.

How to cite this article: Asnani M, Srivastava $\mathrm{K}$, Inam L, Kunwar S. Mayer-Rokitansky-Küster-Hauser Syndrome with Rare Findings of Crossed Fused Renal Ectopia and Ovarian Serous Cystadenoma. J South Asian Feder Obst Gynae 2015;7(3):220-222.

\section{Source of support: Nil}

\footnotetext{
${ }^{1}$ Assistant Professor, ${ }^{2}$ Professor and Head, ${ }^{3}$ Junior Resident ${ }^{4}$ Associate Professor

1-4 Department of Obstetrics and Gynecology, Era's Lucknow Medical College, Lucknow, Uttar Pradesh, India
}

Corresponding Author: Mona Asnani, Assistant Professor Department of Obstetrics and Gynecology, Era's Lucknow Medical College, Lucknow, Uttar Pradesh, India, Phone: 05222408122, e-mail: drdkbajaj@rocketmail.com

\section{Conflict of interest: None}

Date of received: 4 October 2015

Date of acceptance: 3 November 2015

Date of publication: December 2015

\section{INTRODUCTION}

The Mayer-Rokitansky-Küster-Hauser (MRKH) syndrome occurs in one of every 4,000 to 5,000 female births. ${ }^{1}$ The MRKH syndrome is characterized by congenital aplasia of the uterus and the upper part (2/3) of the vagina in women showing normal development of secondary sexual characteristics and a normal 46, XX karyotype. The coelomic epithelium from which the ovaries develop are independent of the müllerian duct from which develops the uterus, cervix and $2 / 3$ of the upper vagina. Therefore, individuals with MRKH syndrome have normal ovaries and they are at normal risk of developing ovarian neoplasms. ${ }^{2}$ Mayer-Rokitansky-Kuster-Hauser may be isolated (type I) but it is more frequently associated with renal, vertebral, and, to a lesser extent, auditory and cardiac defects (MRKH type II or MURCS association). ${ }^{3}$ Müllerian duct aplasia, renal dysplasia and cervical somite anomalies (MURCS) refer to as MURCS association. Primary amenorrhea, sterility and pelvic pain are the main expected gynecological problems in MRKH syndrome.

\section{CASE REPORT}

A unmarried female of 19 years admitted with c/o:

- Pain in lower abdomen and lump in abdomen for 7 months.

- She was having primary amenorrhea.

On examination: Patient was having normal breast development-(tanner stage 4), Normal axillary and pubic hair development-tanner (stage 3). On per abdomen examination, a mass of approximately $8 \times 8 \mathrm{~cm}$ felt in left illiac fossa and lower abdomen tenderness was present. Local examination revealed a small blind vaginal pouch. Rectal examination revealed large left-sided $10 \times 8 \mathrm{~cm}$ cystic mass which was mobile with a smooth surface. Uterus was not palpable. Phenotypic sex was female. 
All the routine investigations with levels of $\mathrm{FSH}, \mathrm{LH}$ came out to be normal. Abdominopelvic ultrasonography revealed left-sided crossed fused renal ectopia and a heterogeneous hypoechoic cystic space occupying lesion with dense internal echoes on left side. Uterus was not visualized. Right ovary was visualized normally. Intravenous pyelography confirmed the finding of left-sided crossed fused renal ectopia (Fig. 1). Magnetic resonance imaging (MRI) findings correspond with ultrasonography (USG) and intravenous pyelogram (IVP) findings. X-ray of chest, lumbosacral spine and cervical spine was normal.

The female and her relatives were counseled and with consent exploratory laparotomy was done.

On laparotomy, a $10 \times 8 \mathrm{~cm}$ cystic hemorrhagic leftsided ovarian mass with a single twist of pedicle was found (Fig. 2). A small hypoplastic unicornuate uterus of approximately $1 \times 1.5 \mathrm{inch}$ was present. Left fallopian tube was attached to the uterus (Fig. 3). The right ovary along with the tube appeared normal, they were present higher up at the level of brim, and were attached to the

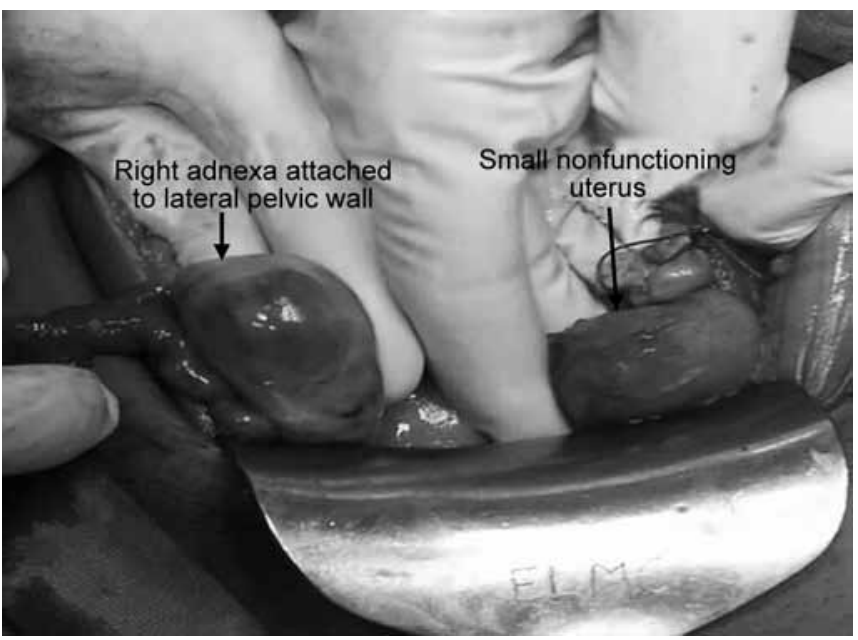

Fig. 1: Surgical anatomy

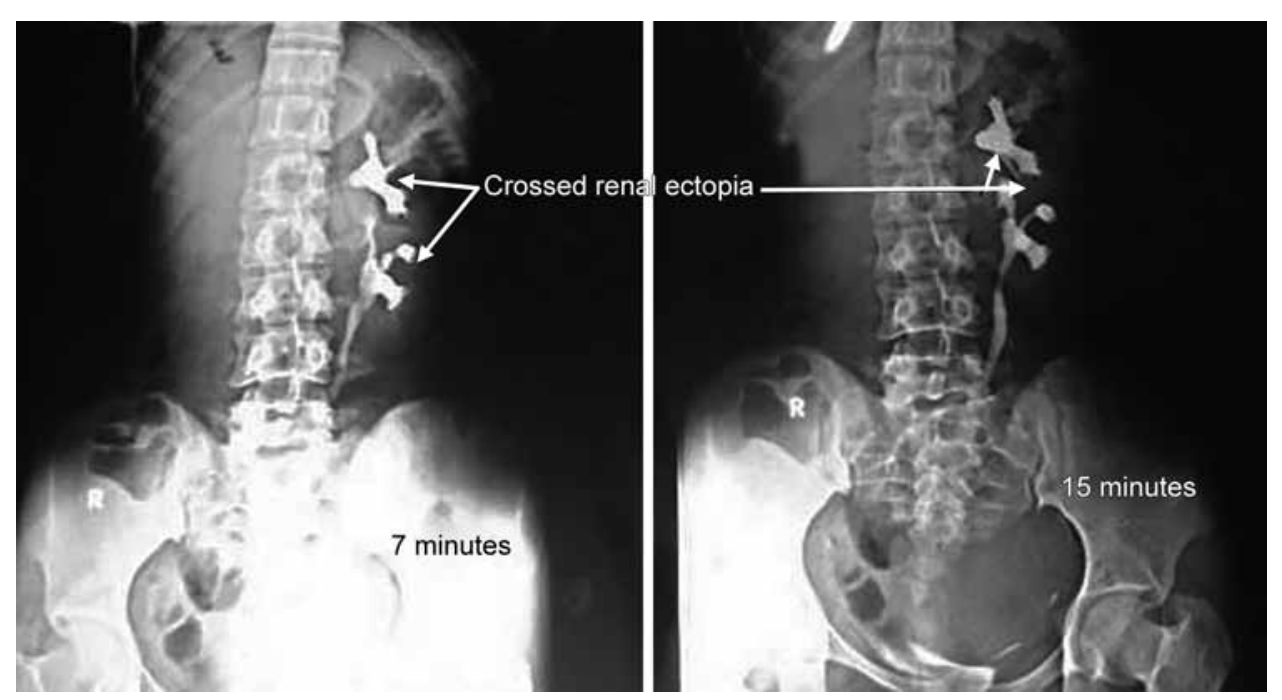

Fig. 3: Intravenous pyelogram of patient pelvic wall. A small hypoplastic unicornuate uterus of approximately $1 \times 1.5$ inch was present. Left-sided Salpingo-oophorectomy was done, and tissue was sent for histopathology. Histopathology report showed an ovarian serous cyst adenoma with evidence of torsion and a normal fallopian tube which was having a patent lumen.

A diagnosis of MRKH type 2 with ovarian serous cystadenoma was made. Postoperative period remained uneventful. Patient is under regular follow-up for screening for the development of ovarian malignancy. She was counseled and planned for surgery to create neovagina once she is emotionally matured and ready to start sexual activity.

Nephrologist opinion was also taken and as the patient was having no urological complains and the kidneys were functioning normally, no intervention was required.

\section{DISCUSSION}

Mayer-Rokitansky-Küster-Hauser syndrome is a rare disorder that affects women. It is characterized by the

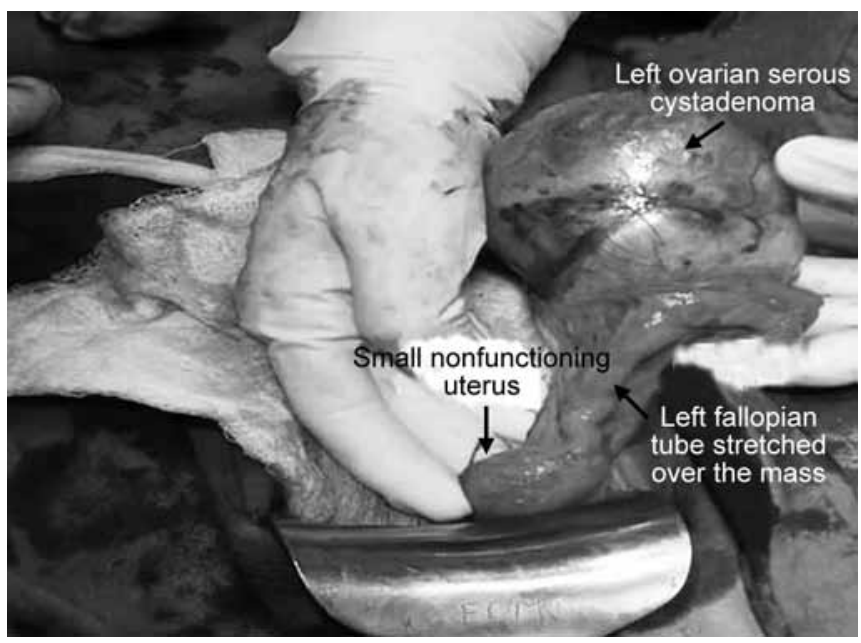

Fig. 2: Surgical steps 
failure of the uterus and the vagina to develop properly in women who have normal ovarian function and normal external genitalia. ${ }^{4}$

Mayer-Rokitansky-Küster-Hauser syndrome is subdivided in two types: type I (isolated) or Rokitansky sequence, and type II or MURCS association. Type I (isolated) MRKH is less frequent than MURCS association. $^{5}$

Clinically, these patients present with primary amenorrhea with a normal female phenotype, normal 46, XX karyotype, and normal and functioning ovaries with no sign of androgen excess. ${ }^{6}$

In our case, müllerian agenesis was associated with crossed fussed renal ectopia and ovarian cystadenoma, so the patient fall into MRKH type 2.

Crossed renal ectopia is defined as the condition, in which a kidney is located on the side opposite from which its ureter inserts into the bladder, and is fused with the other kidney. Crossed-fused renal ectopia (CRE) is one of the rarest anomalies of urinary system. ${ }^{7}$

Having ovarian neoplasms together with this syndrome is an unexpected state. Although very few cases of this association are reported in the literature, it is essential to keep in mind that women with such anomalies should still be followed gynecologically because of the normal risk of developing ovarian neoplasm. ${ }^{8}$

Ulkus $\mathrm{M}$ et al (2002) also reported a case of MRKH syndrome with a borderline ovarian serous cystadenoma. They reported a 43 years women with primary amenorrhea and lower abdominal pain for 3 years, she was diagnosed as a case of MRKH with left ovarian mass. Laparotomy was done and histopathology reported as borderline ovarian serous cystadenoma. ${ }^{9}$

El Khamlichi et al (2011) reported a case of MRKH syndrome in a 21 years old woman who presented with primary amenorrhea, studied with pelvic ultrasonography and MRI, which demonstrated a complete agenesis of uterus, a functional cyst in the right ovary, and a left pelvic ectopic kidney. ${ }^{10}$

\section{CONCLUSION}

All patients with vaginal agenesis must be regarded primarily as a MRKH syndrome and they must be investigated to establish whether there were any associated congenital anomalies.

If there is any symptom like pain in abdomen, they should be thoroughly evaluated for hematometra, any ovarian pathology, and it should be managed accordingly.

\section{REFERENCES}

1. Grifin JE, Edwards C, Madden JD, Harrod MJ, Wilson JD. Congenital absence of the vagina. The Mayer-Rokitansky- KusterHauser syndrome. Ann Intern Med 1976 Aug;85(2):224-236.

2. Folch M, Pigem I, Konje JC. Müllerian agenesis: etiology, diagnosis, and management. Obstet Gynecol Surv 2000 Oct; 55(10):644-649.

3. Varner RE, Younger JB, Blackwell RE. Müllerian dysgenesis. J Reprod Med 1985 Jun;30(6):443-450.

4. Gilliam ML, Shulman LP. Tetrology of fallot, imperforate anus and müllerian, renal and cervical spine (MURCS) anomalies in a 15 years old girl. J Pediatr Adolesc Gynecol 2002;15(4):231-233.

5. Simpson JL. Genetics of the female reproductive ducts. Am J Med Genet 1999 Dec;89(4):224-239.

6. Patel TV, Singh AK. Crossed fused ectopia of the kidneys. Kidney Int 2008 Mar;73(5):662.

7. Jones HW Jr, Mermut S. Familial occurrence of congenital absence of the vagina. Am J Obstet Gynecol 1972 Dec;114(8): 1100-1101.

8. Koonings PP, Al-Marayati L, Schlaert JB, Lobo RA. MayerRokitansky-Kuster-Hauser syndrome associated with endodermal sinüs tumor of the ovary. Fertil Steril 1991 Sep; 56(3):577-578.

9. Ulukuş M, et al. Mayer-Rokitansky-Kuster-Hauser Syndrome with a borderline ovarian serous cystadenoma: a case report. Ege Tip Dergisi 2002;41(4):255-257.

10. El Khamlichi, Allani N, Dairi R. Typical form of MayerRokitansky-Kuster-Hauser syndrome and ectopic kidney. A rare association. Gynecol Obstet Fertil 2011 Feb;39(2):e40-e43. 